\title{
Precise aftershock distribution of the 2019 Yamagata-oki earthquake using newly developed simple anchored-buoy ocean bottom seismometers and land seismic stations
}

\author{
Masanao Shinohara ${ }^{1 *} \mathbb{1}$, Shin'ichi Sakai ${ }^{1}$, Tomomi Okada ${ }^{2}$, Hiroshi Sato ${ }^{1}$, Yusuke Yamashita ${ }^{3}$, Ryota Hino ${ }^{2}$, \\ Kimihiro Mochizuki ${ }^{1}$ and Takeshi Akuhara'
}

\begin{abstract}
An earthquake with a magnitude of 6.7 occurred in the Japan Sea off Yamagata on June 18, 2019. The mainshock had a source mechanism of reverse-fault type with a compression axis of WNW-ESE direction. Since the source area is positioned in a marine area, seafloor seismic observation is indispensable for obtaining the precise distribution of the aftershocks. The source area has a water depth of less than $100 \mathrm{~m}$, and fishing activity is high. It is difficult to perform aftershock observation using ordinary free-fall pop-up type ocean bottom seismometers (OBSs). We developed a simple anchored-buoy type OBS for shallow water depths and performed the seafloor observation using this. The seafloor seismic unit had three-component seismometers and a hydrophone. Two orthogonal tiltmeters and an azimuth meter monitored the attitude of the package. For seismic observation at shallow water depth, we concluded that an anchored-buoy system would have the advantage of avoiding accidents. Our anchored-buoy OBS was based on a system used in fisheries. We deployed three anchored-buoy OBSs in the source region where the water depth was approximately $80 \mathrm{~m}$ on July 5, 2019, and two of the OBSs were recovered on July 13, 2019. Temporary land seismic stations with a three-component seismometer were also installed. The arrival times of P-and S-waves were read from the records of the OBSs and land stations, and we located hypocenters with correction for travel time. A preliminary location was performed using absolute travel time and final hypocenters were obtained using the double-difference method. The aftershocks were distributed at a depth range of $2.5 \mathrm{~km}$ to $10 \mathrm{~km}$ and along a plane dipping to the southeast. The plane formed by the aftershocks is consistent with the focal mechanism of the mainshock. The activity region of the aftershocks was positioned in the upper part of the upper crust. Focal mechanisms were estimated using the polarity of the first arrivals. Although many aftershocks had a reverse-fault focal mechanism similar to the focal solution of the mainshock, normal-fault type and strike-slip fault type focal mechanisms were also estimated.
\end{abstract}

Keywords: 2019 Yamagata-oki earthquake, Aftershock observation, Anchored-buoy system, Ocean bottom seismometer, Shallow water seismic observation

\footnotetext{
*Correspondence: mshino@eri.u-tokyo.ac.jp

${ }^{1}$ Earthquake Research Institute, The University of Tokyo, 1-1-1, Yayoi,

Bunkyo-ku, Tokyo 113-0032, Japan

Full list of author information is available at the end of the article
} 


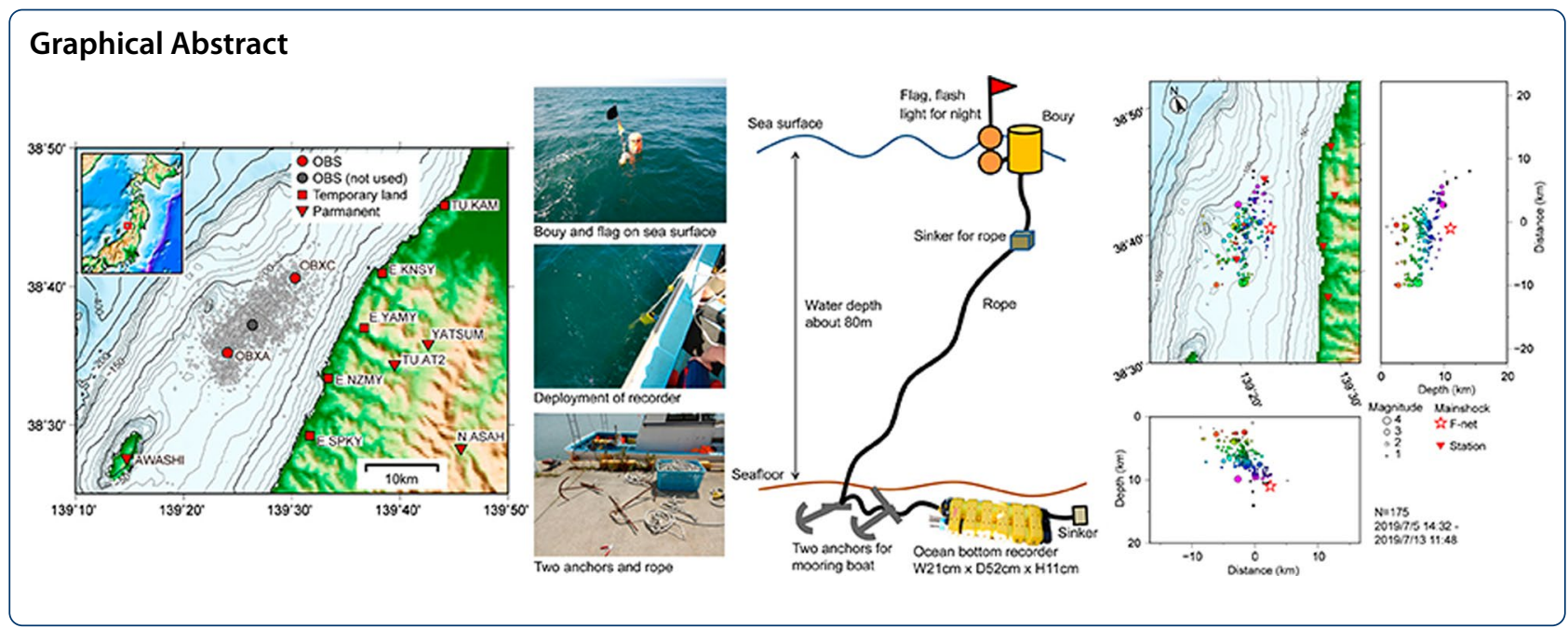

\section{Introduction}

The 2019 Yamagata-oki earthquake, determined by the Japan Meteorological Agency (JMA) with a magnitude $\left(M_{\mathrm{JMA}}\right)$ of 6.7 and a depth of approximately $14 \mathrm{~km}$ occurred in the Japan Sea off Sakata, Yamagata prefecture on June 18 . The maximum seismic intensity of the earthquake was 6 upper on the JMA scale, and a tsunami warning was issued to the coastal regions of the Japan Sea off central Japan. The JMA estimated that the mainshock had a source mechanism of a reverse-fault type with a compression axis of approximately east-west direction. Several large earthquakes have caused damage to communities along the eastern coastal area of the Japan Sea, including the Niigata earthquake $\left(M_{\mathrm{JMA}} 7.5\right)$ in 1964 (Abe 1975), the Nihonkai Chubu earthquake $\left(M_{\text {JMA }} 7.7\right)$ in 1983 (Satake 1985), the Hokkaido Nansei-oki earthquake $\left(M_{\mathrm{JMA}} 7.8\right)$ in 1993 (Tanioka et al. 1995), Chuetsuoki earthquake $\left(M_{\mathrm{IMA}} 6.8\right)$ in 2007 (Miyake et al. 2010), and the Noto Hanto-oki Earthquake $\left(M_{\mathrm{IMA}} 6.9\right)$ in 2007 (Horikawa 2008). It has been estimated that these large earthquakes occurred within the Niigata-Kobe tectonic zone laid in the eastern margin of the Japan Sea (Sagiya et al. 2000). The source region of the 2019 Yamagata-oki earthquake is estimated to be positioned in the tectonic zone. To identify how large earthquakes in the eastern coastal zone of the Japan Sea are generated, it is important to obtain their exact fault plane geometry. Since the source regions of the large earthquakes occurring in the Japan Sea are positioned below marine areas, seafloor seismic observations were carried out to determine the distribution of their aftershocks (Urabe et al. 1985; Aoyagi et al. 1998; Shinohara et al. 2008; Yamada et al. 2008). Precise aftershock distribution estimated from seafloor observations has contributed to identifying the fault geometry of the large earthquakes. The source area of the 2019 Yamagata-oki earthquake is located below the marine area close to the coast of Japan's main island. Seafloor seismic observation is necessary to obtain precise distribution of aftershocks, although the source region is close to the coast (Fig. 1). The 2019 Yamagataoki earthquake was the first large event in the northeastern coastal area of the Japan Sea after the Tohoku-oki earthquake occurred in 2011. The stress field in the northeastern Japan island arc should have been affected by the Tohoku-oki earthquake. In addition, the Niigata earthquake that occurred in the adjacent region (Kusano and Hamada 1991) prior to the 2019 Yamagata-oki earthquake and is believed to had have a similar focal mechanism of reverse-fault type with a steep westward-dipping plane and a gradual eastward-dipping plane (Hirasawa 1965; Abe 1975). From these reasons, we decided to conduct a marine seismic observation in the source region of the 2019 Yamagata-oki earthquake in order to obtain exact lateral and depth distribution of the aftershocks of the mainshock with land seismic observations in the coastal area close to the source region. The source region of the 2019 Yamagata-oki earthquake is situated below the marine area where water depth is less than $100 \mathrm{~m}$. In this shallow depth, it is difficult to observe aftershocks on the seafloor using a conventional free-fall pop-up type ocean bottom seismometer (OBS) (e.g., Kanazawa et al. 2009). Therefore, we developed an anchored-buoy type seafloor seismic observation system for a shallow water depth and obtained seismic records just above the source region of the 2019 Yamagata-oki earthquake. This paper describes the development of the anchored-buoy type OBS, observations using the developed OBSs for shallow water, and the precise aftershock distribution, with particular focus on the depths of the aftershocks using marine seismic stations just above the aftershock region 


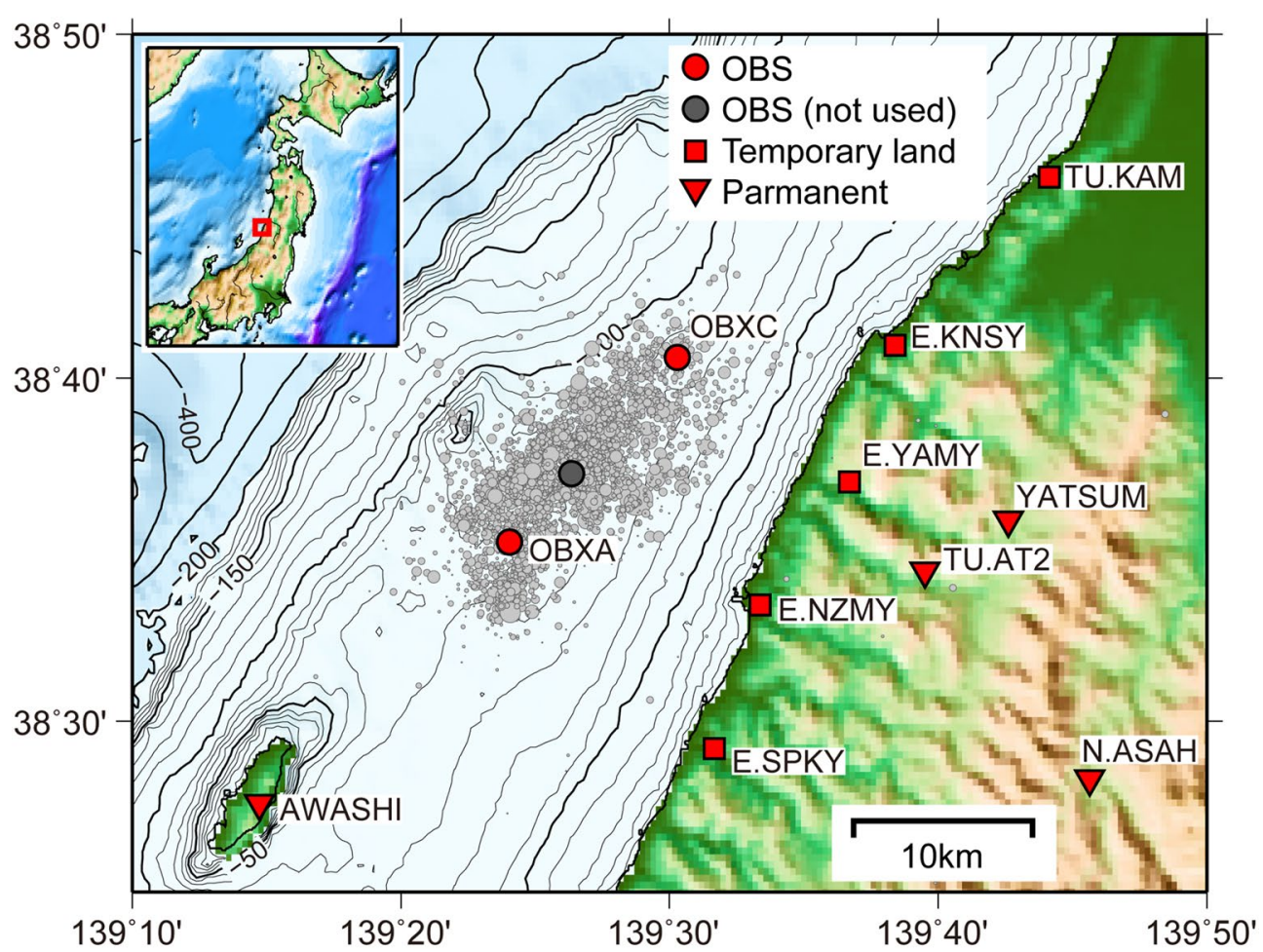

Fig. 1 Location map of developed anchored-buoy OBSs with land seismic stations close to the OBSs. Bathymetric contours in the marine area where the water depth is shallower than $200 \mathrm{~m}$ indicate intervals of water depths of $10 \mathrm{~m}$. Red circles indicate the position of the recovered anchored-buoy OBSs. The gray circle indicates the position of the OBS that could not be recovered. Inverted triangles and squares denote the position of permanent land seismic stations and temporary stations, respectively. Small gray circles denote the epicenter of aftershocks determined by the JMA from June 18 to July 13, 2019. A few OBSs and temporary land seismic stations on the coast are effective for the location of hypocenters

combined with land seismic stations. Furthermore, we discuss focal mechanisms to consider the stress field of the source regions after the 2011 Tohoku-oki earthquake.

\section{Development of simple anchored-buoy ocean bottom seismometer and observation}

Free-fall pop-up type OBSs are currently popular for seafloor seismic observations (Kanazawa et al. 2009). Their advantages include their low cost of production and operation and their operational flexibility. Because popup type OBSs have a buoyancy material, ambient noise becomes greater both with strong seafloor currents and when they are installed on soft sediments (Duennebier and Sutton 1995). As ordinary pop-up type OBSs have a height of approximately $50 \mathrm{~cm}$, a strong current on a shallow seafloor becomes a cause of large ambient seismic noises. In addition, seafloor observations in coastal areas of Japan sometimes interfere with fishery activities. Since the source area of the 2019 Yamagata-oki earthquake has a water depth of less than $100 \mathrm{~m}$, and fishery activities are widespread, it is difficult to perform seafloor seismic observation using ordinary free-fall pop-up type OBSs. Anchored-buoy systems are used as fishing equipment in this region and are presumed to be suitable for seafloor seismic observation systems. According to this concept, we developed a simple anchored-buoy type OBS for shallow water depths (Fig. 2). We adopted an ocean bottom recorder (OBX-750) from Geospace Inc., USA, that would usually be used for seismic surveys in shallow water. The OBX-750 has three velocitysensitive seismometers with a natural frequency of $15 \mathrm{~Hz}$ (GS-ONE OMNI) and a hydrophone. These seismometers are orthogonally installed for three-component seismic observations. Because the sensors can observe properly at any attitude, the OBX-750 has no leveling system for seismic sensors. To monitor the attitude of the package, the recorder has two orthogonal tiltmeters and an azimuth meter. The equipped hydrophone has a flat response in the frequency range greater than $10 \mathrm{~Hz}$. The signals from the scientific sensors are digitized with a resolution of 24 bits and continuously stored to memory. The recording duration is typically 1 month. A package of the OBX-750 has a small size $(52 \times 21 \times 11 \mathrm{~cm})$ and light weight (11 kg in the air and $4 \mathrm{~kg}$ in water). The timing is based on an oven voltage-controlled crystal oscillator (OVCXO). Because the OBX-750 has a flat package, 

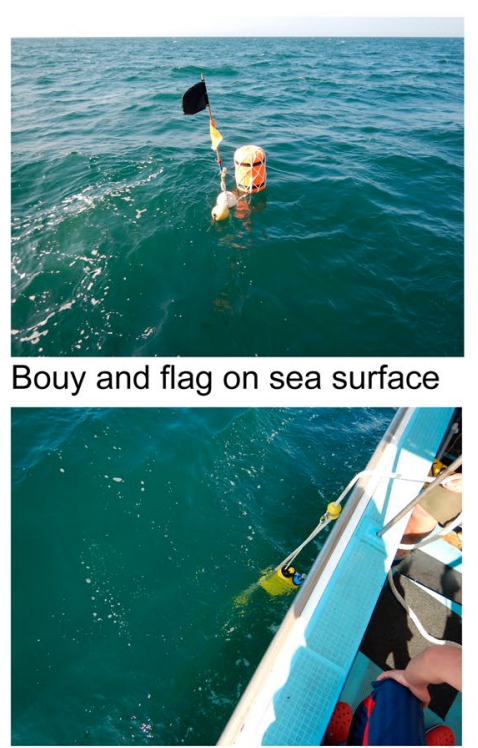

Deployment of recorder

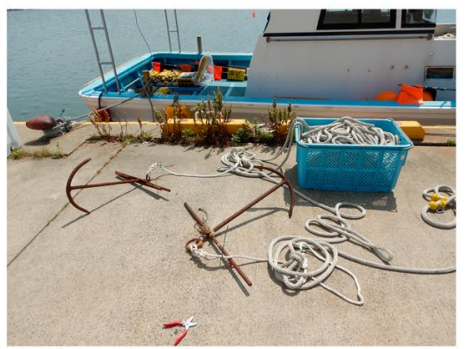

Two anchors and rope

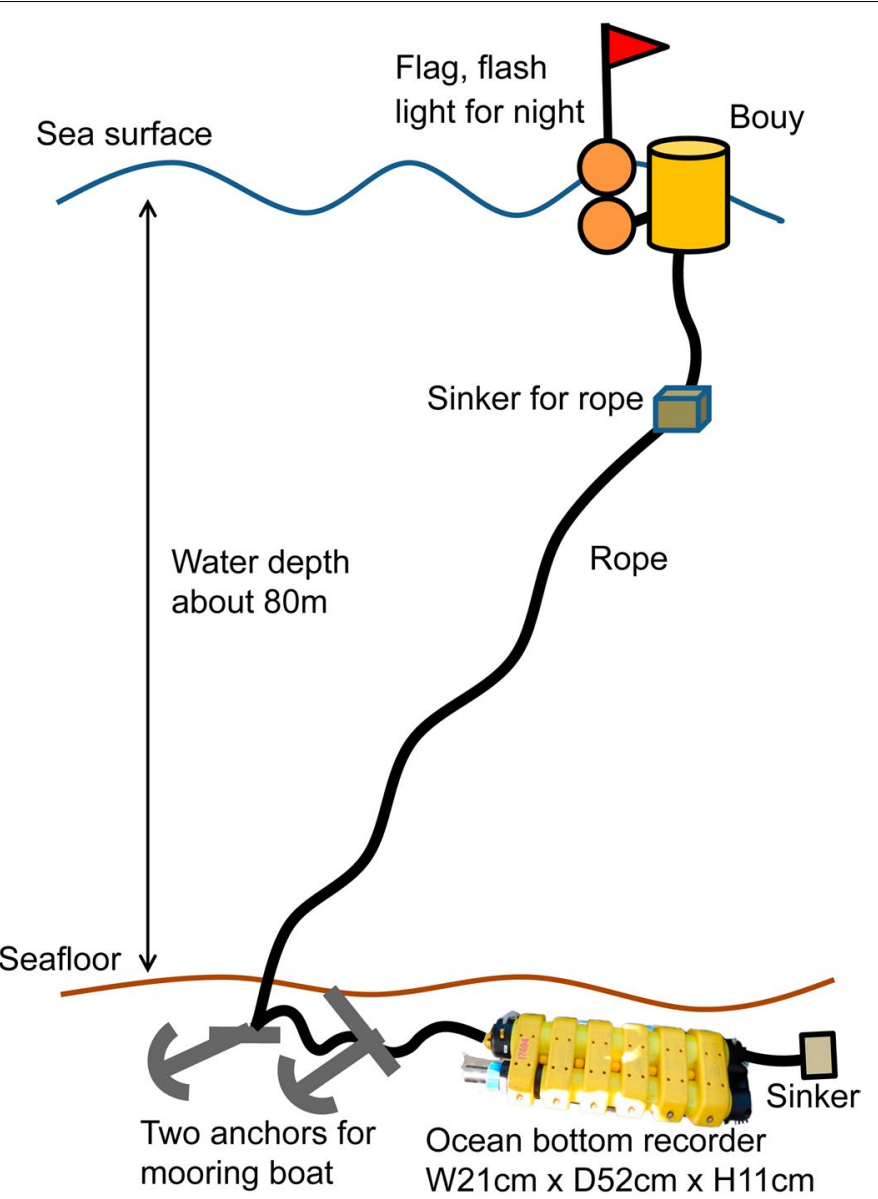

Fig. 2 Photographs and schema of the developed simple anchored-buoy type OBS. Right: the ocean bottom recorder includes a three-component velocity-sensitive seismic sensor, hydrophone, recording unit, and batteries. Because two tiltmeters and an azimuth meter are installed in the package, the records can be converted to vertical and two-horizontal components. The flat shape of the package lowers seismic noise by the seafloor current. A photograph of the recorder is superimposed on the schema of the system. The package of the ocean bottom recorder with sinker and anchors is connected to one end of a long rope, and a buoy is attached to the other end. Left: a small boat can install and recover the simple anchored-buoy OBSs. After the deployment, a buoy with a flag and a flashlight performs the role of a mark on the sea surface for other boats

a seafloor current should have a small effect on ambient seismic noises on the seafloor. The recorder is expected to lie under the seafloor in an environment of soft sediment due to its lack of flotation and flat shape. For installation of the OBX-750 on the seafloor at a shallow depth, we decided to employ an anchored-buoy OBS that was modified from an anchored-buoy system for fishing (Fig. 2) which has the advantage, with the buoy on the surface, of being able to inform surrounding boats of the system's position. At one end of a rope, a 2-kg weight was attached for stable deployment, and the OBX-750 was joined at the other end of the rope that has a length of $1.5 \mathrm{~m}$. Two anchors $(8 \mathrm{~kg})$ that were originally used to hold a small boat were attached at a 2-m interval from the recorder using the other rope. Such anchors are useful for preventing movement of the system caused by wind and waves. A long rope with a length of approximately $175 \mathrm{~m}$ connected the anchors and a buoy. Another weight $(2 \mathrm{~kg})$ was joined at a distance of $20 \mathrm{~m}$ from the buoy to stretch the rope just below the buoy vertically. We deployed three anchored-buoy OBSs in the source region at intervals of $5 \mathrm{~km}$ and $8.5 \mathrm{~km}$ (Fig. 1). A small boat was used for installation and recovery of the anchored-buoy system (Fig. 2). Water depths were approximately $80 \mathrm{~m}$. We chose a gain of $18 \mathrm{~dB}$ for an amplifier and low-cut filter of $1 \mathrm{~Hz}$, since large ambient seismic noise was expected due to shallow water depth. The amplified signals through an anti-alias filter were digitized with a sampling frequency of $500 \mathrm{~Hz}$. The systems were deployed on July 5, 2019, 17 days after the occurrence of the mainshock. Although the number of aftershocks had decreased, the active region for these seemed not to have changed from the region just after the mainshock according to hypocenter determination by the JMA (Additional file 1: Fig. 

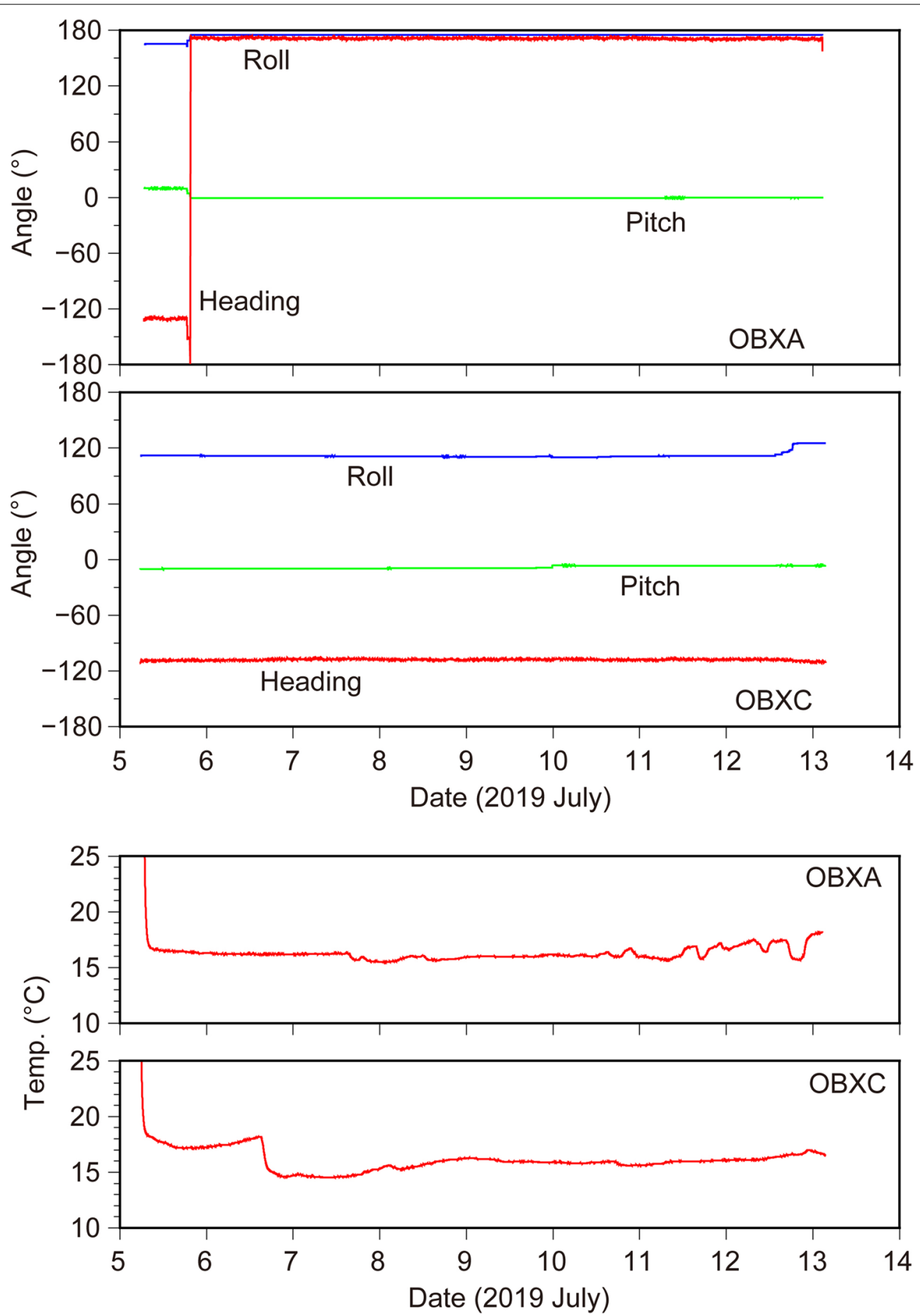

Fig. 3 Temporal variation of attitudes and temperature of the recording packages. Upper: roll, pitch and heading angles are plotted with time for two recording units. OBXA (the southern station) and OBXC are estimated for installation on the seafloor covered with sand and rocks, respectively. Angles are generally stable during the observation, although the attitude of OBXA largely changed on June 5, 2019. It is possible that the recording package was pulled. Lower: temporal changes of temperature for both units are also small, except for June 6th for OBXC. A small variation in temperature of the unit lowers the error of the timing, which is based on a crystal oscillator in the unit 
S1). Unfortunately, it was found that one buoy had disappeared from the sea's surface at the deploying position on July 12, and we carried out recovery of the systems on July 13. Two anchored-buoy OBSs were successfully recovered, and we obtained their data. According to the crew of the boat performing the installation and recovery, the seafloor of the southern (OBXA) and northern (OBXC) stations seemed to be covered with sand and rocks, respectively. Time differences between the clock of the recorder driven by OVCXO and the time signal from the global navigation satellite system (GNSS) were measured just before the deployment and just after the recovery for the time adjustment of the clock in the recorders. Temporary land seismic stations had a three-component seismometer. One station used a seismometer with a natural period of $120 \mathrm{~s}$, seismometers for the other stations had a natural frequency of $1 \mathrm{~Hz}$. The data recorded simultaneously with the seafloor observation on both the permanent and temporary stations were also retrieved (Fig. 1).

\section{Data and hypocenter location}

The OBX-750 recorded angles of roll and pitch of the housing and heading (azimuth) at an interval of $1 \mathrm{~min}$ during a seismic recording. It was found that the recorders were positioned stably on the seafloor during the observation (Fig. 3). For the OBXA, the heading had a large change after the deployment. At this large change of heading for the OBXA, the pitch and roll varied, and there is a possibility that the buoy on the sea surface had pulled the recorder slightly. A strong wind with a maximum speed of $10 \mathrm{~m} / \mathrm{s}$ was observed on the coast during the large change of heading for the OBXA. When a small change of attitude occurred before the recovery of the OBXC, a strong wind was also recorded. The temperature of the recorders was registered at every $1 \mathrm{~min}$ for the entire recording period (Fig. 3). This temperature decreased rapidly after the deployment, to reach approximately $17{ }^{\circ} \mathrm{C}$, and although it was generally stable, there was a small variation that is thought to correspond with a change in sea water temperature.

We can convert the three-component orthogonal seismic data from the OBX-750 to three-component data for up-down, north-south, and east-west directions using information from the attitude of the recorder. Because the attitude was measured at an interval of $1 \mathrm{~min}$, we divided the seismic data into 1-min batches and applied the conversion (Fig. 4). The conversion of the seismic data was useful for identifying the arrival of the P- and $\mathrm{S}$-waves. After the conversion of the seismic data, we estimated the ambient seismic noise spectra of the records obtained on the shallow seafloor.

A large ambient seismic noise was expected due to the shallow water depth. We evaluated the noise levels in the shallow water using the direction-corrected data obtained from the anchored-buoy OBS that we had developed. First the velocity records of the seismometers were differentiated to transform to acceleration. The power spectra of the corrected data were estimated with a time window of about $33 \mathrm{~s}$ at intervals of $1 \mathrm{~min}$ for all observation periods. We calculated their average using smoothing in the frequency domain. A total of 11,411 spectra were obtained, and we calculated the probability density functions (McNamara and Buland 2004; McNamara and Boaz 2006) of the power spectra (Fig. 5). The ambient seismic noise levels of the anchored-buoy OBSs were positioned between the Low Noise Model and the High Noise Model in the frequency range less than $10 \mathrm{~Hz}$ (Peterson 1993). Although there is no information for typical noise levels in the frequency range higher than $10 \mathrm{~Hz}$, the ambient noise levels of both vertical and horizontal components are comparable to those obtained in the deep ocean. The noise levels of the anchored-buoy OBSs could be compared to those of the close land stations, and the noise levels were equivalent (Fig. 5). This means the detectability of the anchored-buoy type OBSs is comparable with those of land seismic stations. Because the seismometers in the OBX-750 are moving coil type with a natural frequency of $15 \mathrm{~Hz}$, the noise levels decreased in the frequency range lower than $15 \mathrm{~Hz}$. In addition, we estimated temporal noise level variation for vertical and horizontal components using the obtained spectra. All spectra at an interval of 1 min were plotted as a function of time (Additional file 1: Fig. S2). Although the noise levels sometimes became greater, the level was generally stable. There is a possibility that boats were operating near the stations when the noise in the records became greater. We could compare the noise levels of the anchored-buoy OBSs to maximum wind speed observed by a weather station installed close to our seismic network (AMeDAS, JMA) and maximum wave height observed by GPS buoy off Yamagata Prefecture

\footnotetext{
(See figure on next page.)

Fig. 4 Example of seismograms from the anchored-buoy OBSs and temporal land seismic stations for an earthquake. Three-component records are shown. The records of the OBSs have been converted from original records using information from tiltmeters and the azimuth meter. No filter has been applied. The estimated coordinates of the epicenter of the event are $38.66^{\circ} \mathrm{N}, 139.44^{\circ} \mathrm{E}$. The depth and magnitude of the event are $9.9 \mathrm{~km}$ and 3.7, respectively. The station is labeled above the vertical component. Black bars on the north-south component indicate the scale of amplitude in velocity. Root-mean square averages of amplitude for the first $0.5 \mathrm{~s}$ are shown by numerals. Solid and open inverted triangles indicate P- and S-wave arrivals, respectively
} 


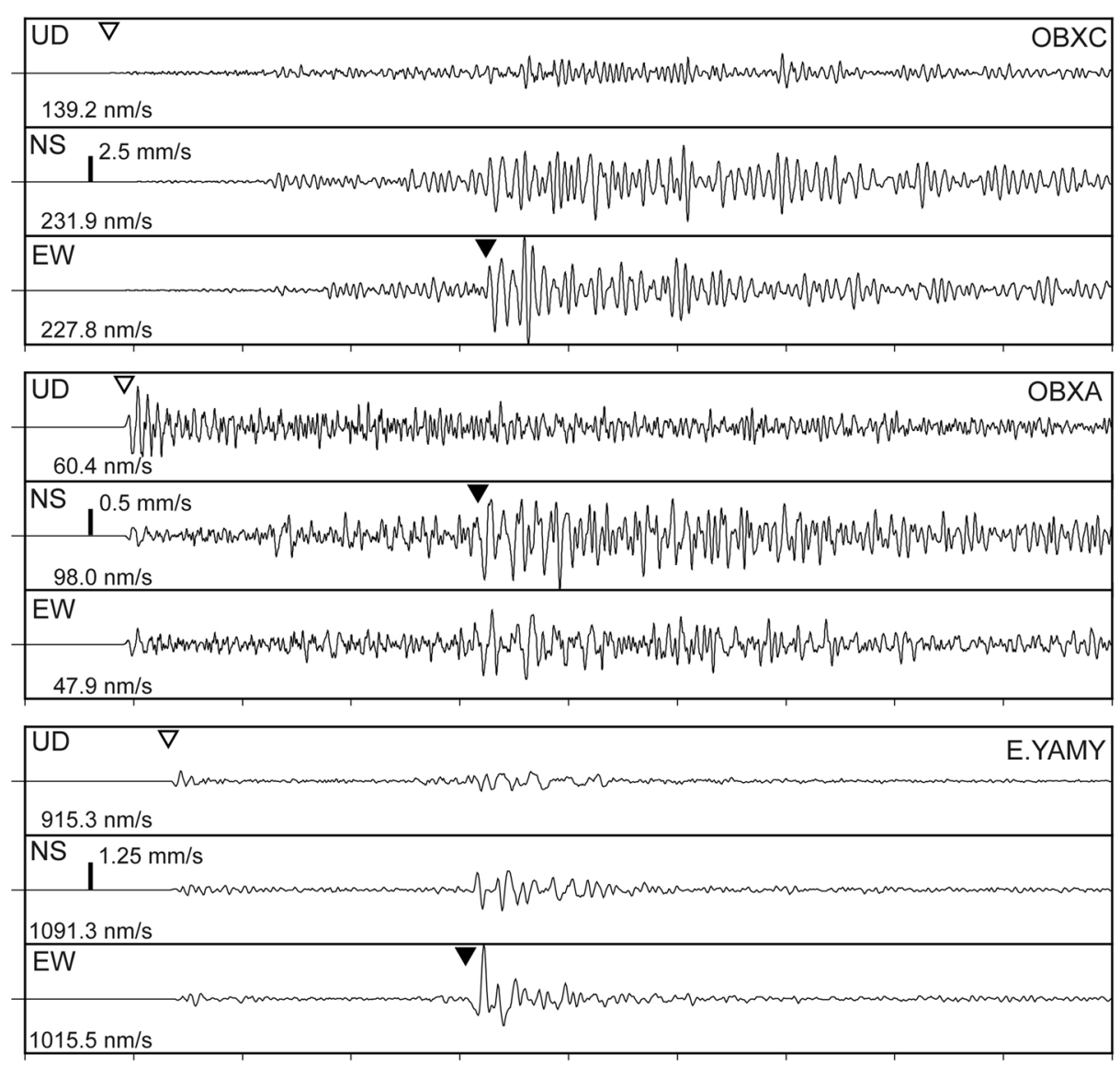

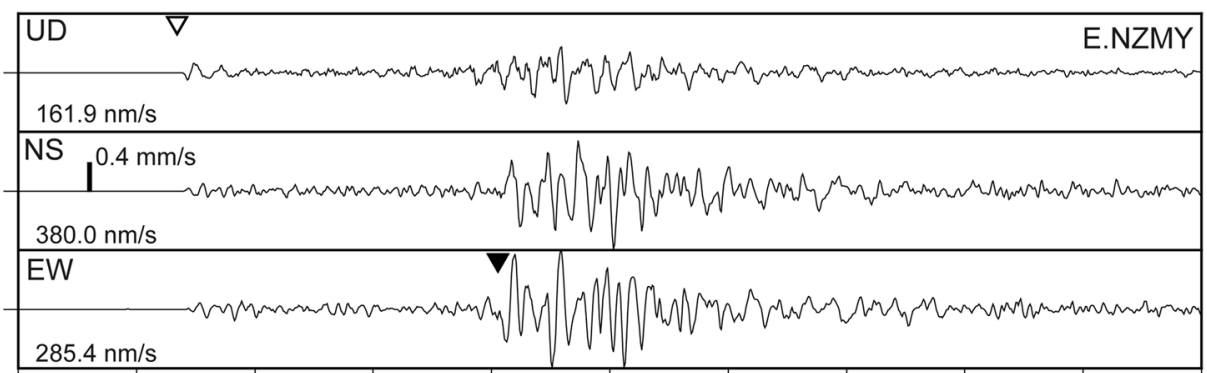

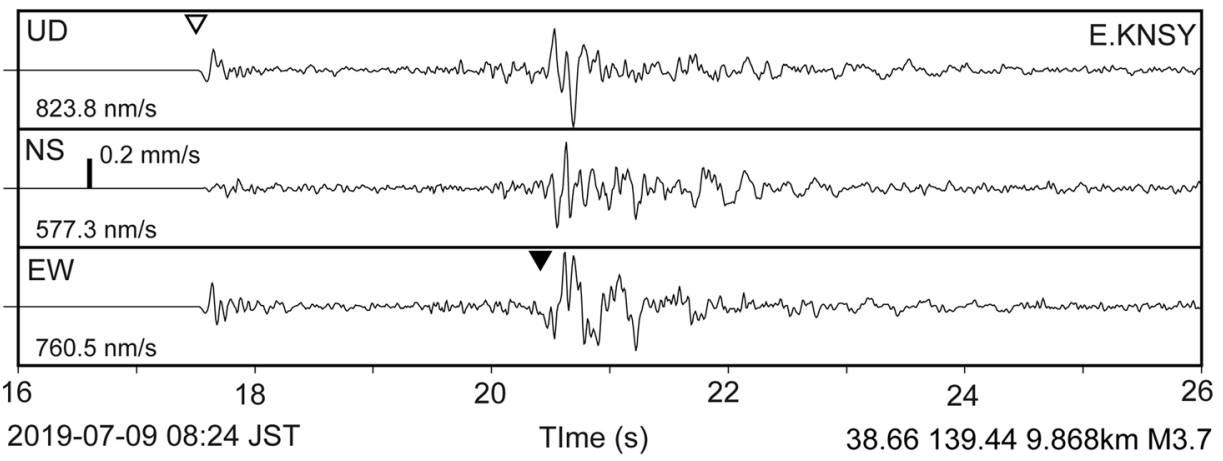

Fig. 4 (See legend on previous page.)

No filter 

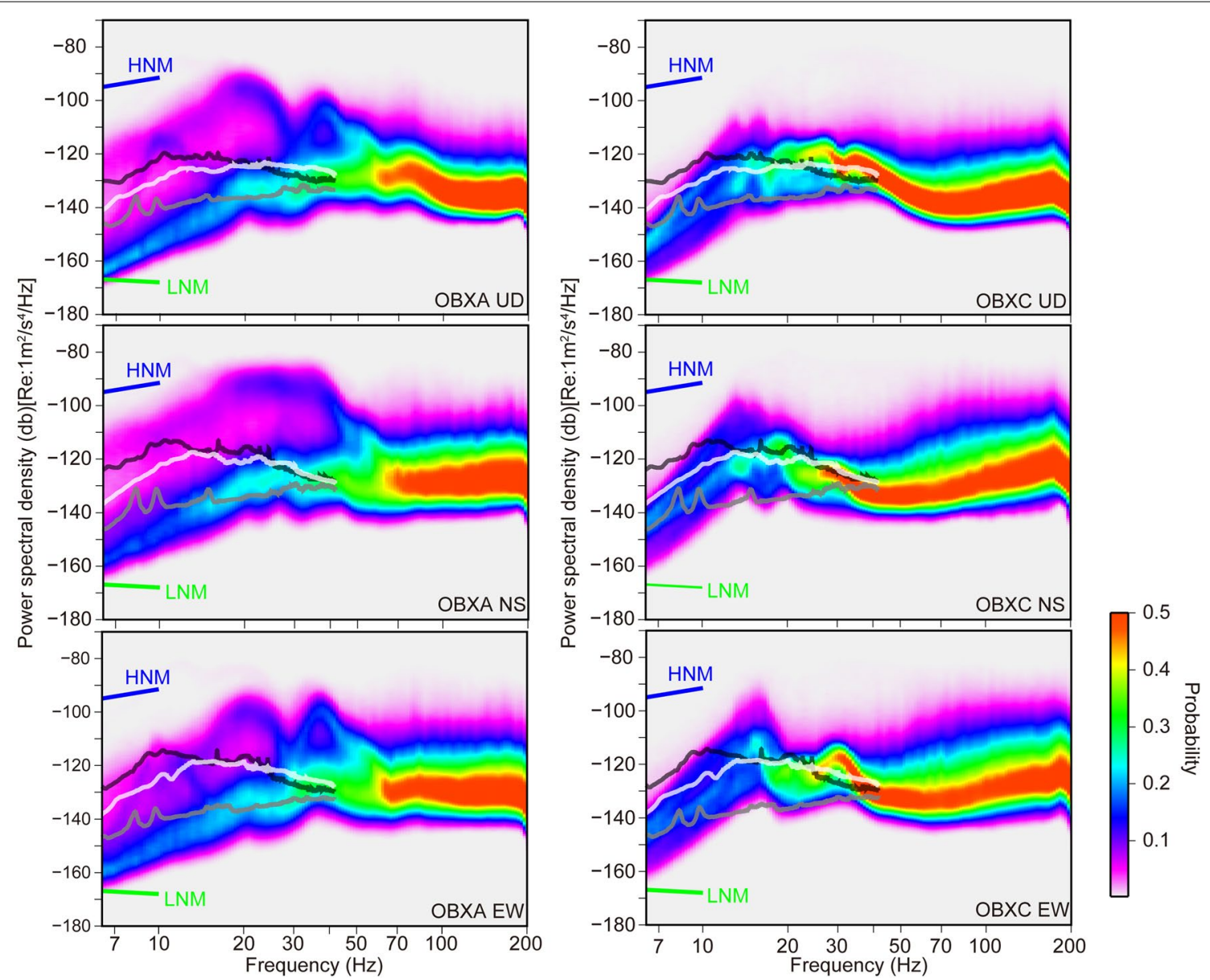

Fig. 5 The probability density function of ambient seismic noise spectra from three-component records of the anchored-buoy OBSs. The original data from the OBSs have been converted to the records for up-down, north-south and east-west directions using information on the attitude of the packages. Data from 14:31 on July 5, 2019, to 12:14 on July 13,2019, were used for the estimation. We estimated spectra every 1 min with a time window of $32.768 \mathrm{~s}$, and probability was estimated using 11,411 spectra. Although the seismic sensors of the anchored-buoy OBS have a natural frequency of $15 \mathrm{~Hz}$, the sensor response was not compensated for the estimation. The High Noise Model and Low Noise Model of Peterson (1993) are shown in frequencies lower than $10 \mathrm{~Hz}$. Black, gray, and white lines indicate averages of seismic noise spectra for the same period from the records of the land stations, E.NZMY, E.KNSY, and E.YAMY, respectively. A 15-Hz high-pass filter was applied for data from the land stations to compare those from the anchored-buoy OBSs. The ambient noise levels of the anchored-buoy OBSs are sufficiently small to pick up arrivals and comparable to the land stations, in spite of shallow water depths. It is believed that the flat shape of the recorder is effective for reducing ambient noises

(NOWPHAS) operated by Port Bureau, Ministry of Land, Infrastructure, Transport and Tourism (Additional file 1: Fig. S2). The noise levels around $10 \mathrm{~Hz}$ seem to correlate to the wind speed and the wave height. Consequently, we were able to confirm that observation using the developed anchored-buoy system for the shallow seafloor because the noise levels were low enough on the records for small earthquake observation throughout the observation period. Reflecting the low and stable noise level, many aftershocks were unexpectedly recorded by the anchored-buoy OBSs including microearthquakes with magnitudes of less than 1.0 (Additional file 1: Fig. S3).
The time of the individual records by the anchoredbuoy OBSs was adjusted using comparative information between GNSS timing and the clock in the recorder. After the time adjustment, all seismic data were combined into multi-station waveform data files with a duration of $1 \mathrm{~min}$. Our network consisting of the anchored-buoy OBSs, permanent and temporary land stations had a total of 16 seismic stations (Additional file 1: Table S1). Then the arrival times of the $\mathrm{P}$ - and $\mathrm{S}$-waves were read manually from the records of the anchored-buoy OBSs and land stations on a computer display (Urabe and Tsukada 1991), based on the event list determined by the JMA 


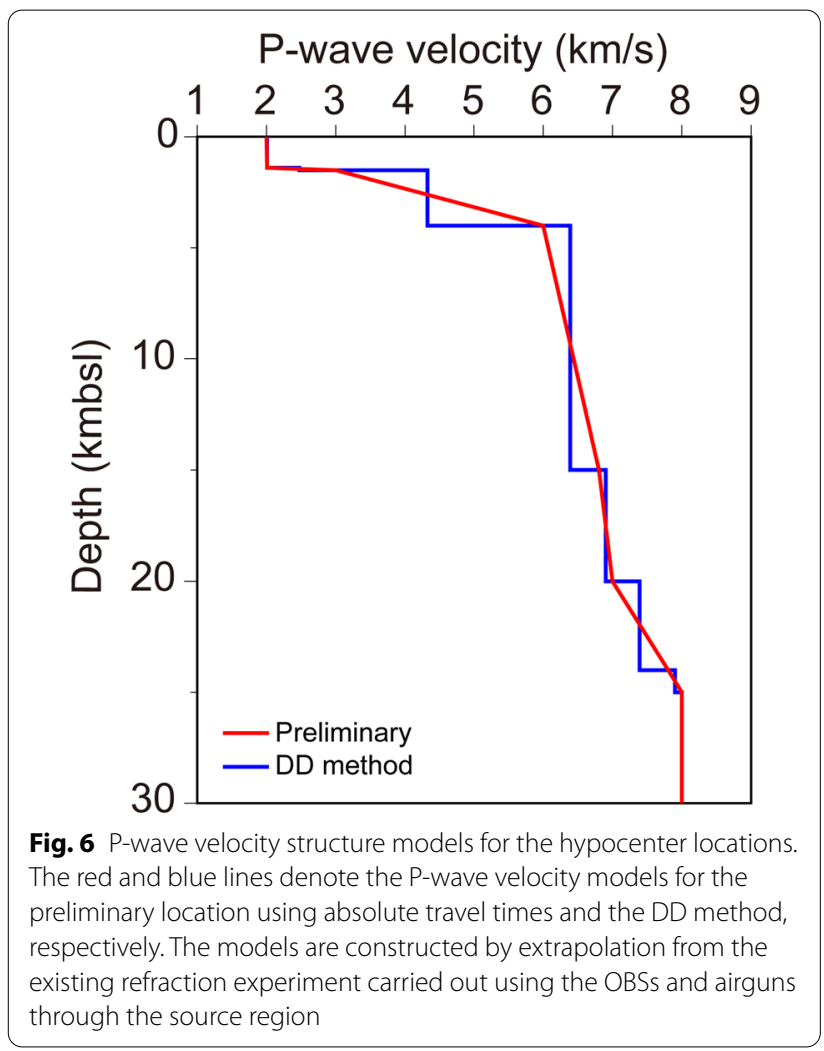

(Fig. 4). In addition, some small aftershocks that had not been listed in the JMA catalogue were also processed. We could pick up the arrival time and largest amplitude for a total of 181 aftershocks. For large events, we also read the polarities of the first arrivals to determine the focal mechanism of the events.

An exact velocity structure under the region is necessary for the location of the aftershock with spatial highresolution. A seismic survey using OBS, multichannel hydrophone streamer, and airguns was performed in 2010 (Sato et al. 2014). The profile was laid from the coastal area to the Yamato Basin in the Japan Sea and intersected the source region of the 2019 mainshock. Because the active region of the aftershocks was relatively narrow, a one-dimensional velocity structure seemed to be enough for the hypocenter location. Since the source area is close to the coast of Japan's main island, the existing seismic survey cannot determine the velocity structure with high resolution for that region (Sato et al. 2014). We estimated a simple, one-dimensional seismic wave velocity structure for the hypocenter location from the results of the marine seismic survey by extrapolation (Fig. 6). From the results of the seismic survey, the crust seemed to have a thickness of approximately $25 \mathrm{~km}$ and comprised a sedimentary layer, upper and lower crust. The sedimentary layer had a constant P-wave velocity of
$2.0 \mathrm{~km} / \mathrm{s}$, the upper crust had P-wave velocities of 3.0 $6.8 \mathrm{~km} / \mathrm{s}$ and a thickness of $13.5 \mathrm{~km}$, and the lower crust had P-wave velocities of $7.0-7.8 \mathrm{~km} / \mathrm{s}$. For the $\mathrm{S}$-wave structure, we assumed a $V_{\mathrm{p}} / V_{\mathrm{s}}$ ratio of 1.73 for all layers. A P-wave velocity in the uppermost mantle was assumed to be $8.0 \mathrm{~km} / \mathrm{s}$. We constructed a one-dimensional velocity structure whereby the velocity would increase continuously with depth for the preliminary location. Then we transferred the continuous velocity structure to the velocity structure, whereby each layer had constant velocities for another location program. The velocity and thickness of the uppermost layer should have varied beneath each seismic station. Therefore, a compensation of calculated travel time for the location was necessary for high resolution.

We first located hypocenters of the aftershock using the location program with absolute travel times and the maximum-likelihood estimation technique (Hirata and Matsu'ura 1987). Thick sedimentary layers with low seismic velocity were estimated below the seismic stations and the anchored-buoy OBSs in particular. First, the hypocenter location was carried out using P- and S-wave arrival times with assumed values of station correction for the velocity structure. We calculated the average of differences between observed and estimated travel time using the velocity structure (O-C times) for each station from the results of the location, and the averages of $\mathrm{O}-\mathrm{C}$ times were added to the previous station correction. Then the hypocenter location was performed again using the new values of the station correction. This procedure was repeated three times and we obtained appropriate values of each station correction (Additional file 1: Fig. S4). Next, we relocated the hypocenter using the double-difference (DD) method (Waldhauser and Ellsworth 2000) to obtain more precise positions for the aftershocks. Because the location program for the DD method accepts a velocity structure with constant velocity in layers, we used the velocity structure that was consistent with that of the first location using absolute travel times. We estimated the magnitude of the aftershocks by the maximum amplitudes of the seismic data obtained from the land stations (Watanabe 1971).

\section{Results}

After the preliminary hypocenter location, we could locate all the aftershocks under a convergent condition with the obtained station corrections. The location program for the preliminary hypocenter determination calculated errors for each aftershock location from the covariance matrix for the nonlinear inversion (Hirata and Matsu'ura 1987). For station corrections that compensate heterogeneity just below the stations, marine stations need large compensations for the calculation 
of travel times (Additional file 1: Fig. S4). P- and S-wave station corrections for the marine stations were greater than $0.71 \mathrm{~s}$ and $2.2 \mathrm{~s}$, respectively. On the other hand, the station corrections for the land stations were smaller than $0.25 \mathrm{~s}$ and $0.55 \mathrm{~s}$, respectively. This meant that the observed arrival times at marine stations were late compared to the arrivals calculated using the velocity model. The marine stations were estimated to have a thick sedimentary layer with slow seismic velocity. The average location errors were $0.28 \mathrm{~km}$ in the horizontal direction and $0.58 \mathrm{~km}$ in depth direction. Our temporary seismic network has the capability to locate aftershocks with substantially high resolution within the seismic network. Using the preliminary hypocenter location of 181 aftershocks, we relocated the hypocenters using the DD method (Waldhauser and Ellsworth 2000). After the DD relocation using the hypocenters determined by the absolute travel times, the hypocenters of 175 aftershocks were relocated with spatial high resolution (Fig. 7). Several aftershocks could not be located throughout the grouping procedure of the DD method.

The depth of the aftershocks ranged from 2.5 to $10 \mathrm{~km}$, and the active area of aftershocks was limited under the marine area; most of the aftershocks occurred within an area of $8 \times 20 \mathrm{~km}$. Those that occurred in the northeastern part had greater depth than those in the southwestern part. The aftershocks seemed to be positioned along a plane dipping down toward the southeast. The hypocenter distribution was not spatially uniform in the active region of the aftershocks. The determined magnitudes of the aftershocks ranged from 0.3 to 4.6. Seismicity in the active area was generally constant in terms of the occurrence of events over the observation period.

\section{Discussion}

The aftershocks that we could locate using the data from the anchored-buoy OBSs and the land seismic stations were also analyzed by the JMA using the permanent land seismic network. Therefore, our results are comparable with those reported by the JMA (Additional file 1: Fig. S5). We searched events from the JMA report by comparison of origin time, and 173 events in the JMA report corresponded with our results. The active regions determined by the epicenters from our results and the JMA report were positioned in almost the same area. Most of the aftershocks determined by the JMA in the study region had depths from 10 to $18 \mathrm{~km}$, which was approximately $5 \mathrm{~km}$ deeper than the aftershock depths we located. The further the hypocenter was from the coast of the main Japanese island, the greater the difference in depth between our results and the hypocenters determined by JMA seemed to become. The events in the marine area were determined to be deeper by using only the permanent land seismic network data. Since our seismic network included the anchored-buoy OBSs positioned above the active region of aftershocks, the depths of the events were estimated with a high resolution. We could also compare the magnitudes determined by the JMA and our analysis (Additional file 1: Fig. S5). The magnitudes in our results were mainly estimated from maximum amplitude obtained at land seismic stations. Although our magnitudes were slightly larger than those determined by the JMA, those estimated by our networks were consistent with the magnitudes by the JMA.

The absolute depth of the events depended on the velocity structure during the location. In this study, the velocity model for the hypocenter location (Fig. 6) was estimated using information of the velocity structure estimated by the previous marine seismic survey (Sato et al. 2014). In addition, a thick sedimentary layer that had a very low S-wave velocity below the seafloor and local heterogeneity just below the stations affected the estimation of the absolute depth of the events. The travel times had to be compensated for the sedimentary layer and local heterogeneity during the preliminary location using the absolute travel times. Due to the availability of the adopted velocity structure retrieved from the seismic survey (Fig. 6) and the appropriate adjustment of the travel times by the station correction method (Additional file 1: Fig. S4), the absolute depths of the aftershocks in this study are believed to have a high reliability. Because most of the aftershocks in this study were distributed from depths of $2.5 \mathrm{~km}$ to $10 \mathrm{~km}$, the activity of the aftershock was concentrated in the upper part of the upper crust. In addition, the deepest aftershock occurred at a depth of about $15 \mathrm{~km}$ throughout the observation. It is inferred that the source region of the 2019 Yamagata-oki earthquake was limited to the upper crust.

The National Research Institute for Earth Science and Disaster Resilience (NIED) reported information about the hypocenter and focal mechanism of the 2019 Yamagata-oki earthquake determined by moment tensor inversion (NIED 2021). According to their result, the moment magnitude was 6.4 and one of the nodal planes had a strike of $23^{\circ}$ and dip of $36^{\circ}$ for the mainshock. The aftershocks formed a plane dipping to the southeast from the cross-section of the aftershock distribution projected on the vertical plane with an azimuth of $23^{\circ}$ (Fig. 7). The dip angle of the plane formed by aftershocks was consistent with that of that of the nodal plane of the mainshock estimated by the moment tensor inversion. The plane dipping toward the southeast had a size of approximately $20 \mathrm{~km} \times 10 \mathrm{~km}$, considering the dip angle. The size of the plane formed by the aftershocks was comparable to the magnitude of the mainshock. The hypocenter of the mainshock estimated by the NIED 


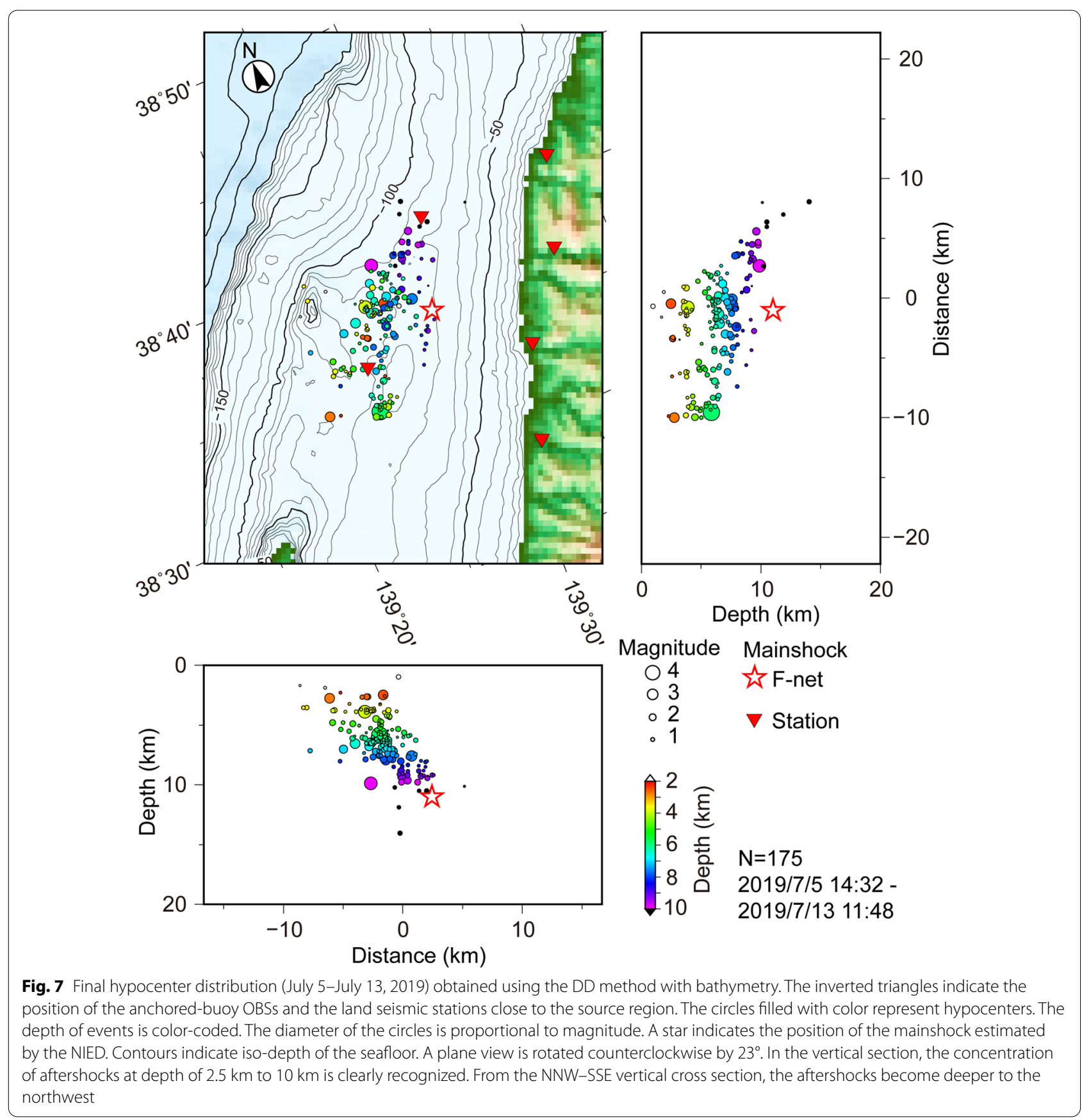

using moment tensor inversion was positioned at the bottom of the plane formed by the aftershock. The rupture of the mainshock was estimated to be propagated from the deep region to the shallow region. Although a plane dipping to the southeast was obviously recognized in the vertical section, there were some events away from the plane (Fig. 7). Since the number of aftershocks that were located by our marine observation was limited, due to the short observation period, it is difficult to identify that these events formed other planes from our result. Yoshida et al. (2020) obtained the spatiotemporal distribution of the aftershocks of the mainshock using data from permanent land seismic stations and found three planar structures of aftershocks. The largest plane of their result seems to be related to the plane estimated from our results. The aftershocks away from the plane in this study may correspond to the other two planes reported in Yoshida et al. (2020). Some previous 
large earthquakes occurring in the eastern margin of the Japan Sea had a few planar structures of aftershocks. Shinohara et al. (2008) reported that the aftershocks of the 2007 Chuetsu-oki earthquakes with a JMA magnitude of 6.8 formed at least two planes that consisted of a conjugate fault system. Such a complex fault system was also observed during the aftershock activity of the 2004 midNiigata prefecture earthquake (Kato et al. 2007). There is a possibility that the 2019 Yamagata-oki earthquake had one large fault plane and small conjugated faults. The 1964 Niigata earthquake occurred in the adjacent region of the mainshock, and the focal mechanism of the Niigata earthquake (Hirasawa 1965) closely resembled that of the mainshock. There is controversy over the fault plane for the Niigata earthquake. Satake and Abe (1983) argued that the fault plane was an eastward-dipping plane with a low angle, to explain seafloor deformation. From teleseismic P-waves and the relocation of aftershocks, the eastward-dipping fault model was also preferred (Mori and Boyd 1985). The steeply westward-dipping fault model was supported by analysis of the aftershocks (Kusano and Hamada 1991) and strong motion records (Shiba and Uetake 2011). The 2019 Yamagata-oki earthquake obviously had a gradual eastward-dipping fault from the aftershock distribution; however, the existence of small, conjugated faults shows the complexity of tectonics in this region.

During the reading of the P-and S-waves, we also read the polarity of the first arrivals from large aftershocks. From data for the polarity of the first arrivals picked from waveforms, the focal mechanisms of 21 aftershocks were estimated using the program of Reasenberg and Oppenheimer (1985). The data from the anchored-buoy OBSs and the temporary land seismic stations close to the OBSs were effective for estimating focal mechanisms, since these stations were positioned right above the aftershocks. For determination of the focal mechanism, information about the hypocenters obtained from the location program using absolute travel times was used to calculate azimuth angle and the take-off angle of seismic rays. The magnitudes of the events that could estimate focal solution were greater than 1.9. Most of the events had a focal mechanism related to the WNW-ESE compressional stress (Fig. 8). There are many focal mechanisms of reverse fault that are comparable with the focal solution of the mainshock, as Yoshida et al. (2020) have already indicated. In other words, most of the aftershocks with reverse-fault type mechanism had a nodal plane parallel to the plane formed by the aftershocks. However, some aftershocks had a strike-slip fault type focal mechanism or a normal-fault type focal mechanism. There is a catalog of focal solutions determined by automated moment tensor determination that uses the Japanese land broadband

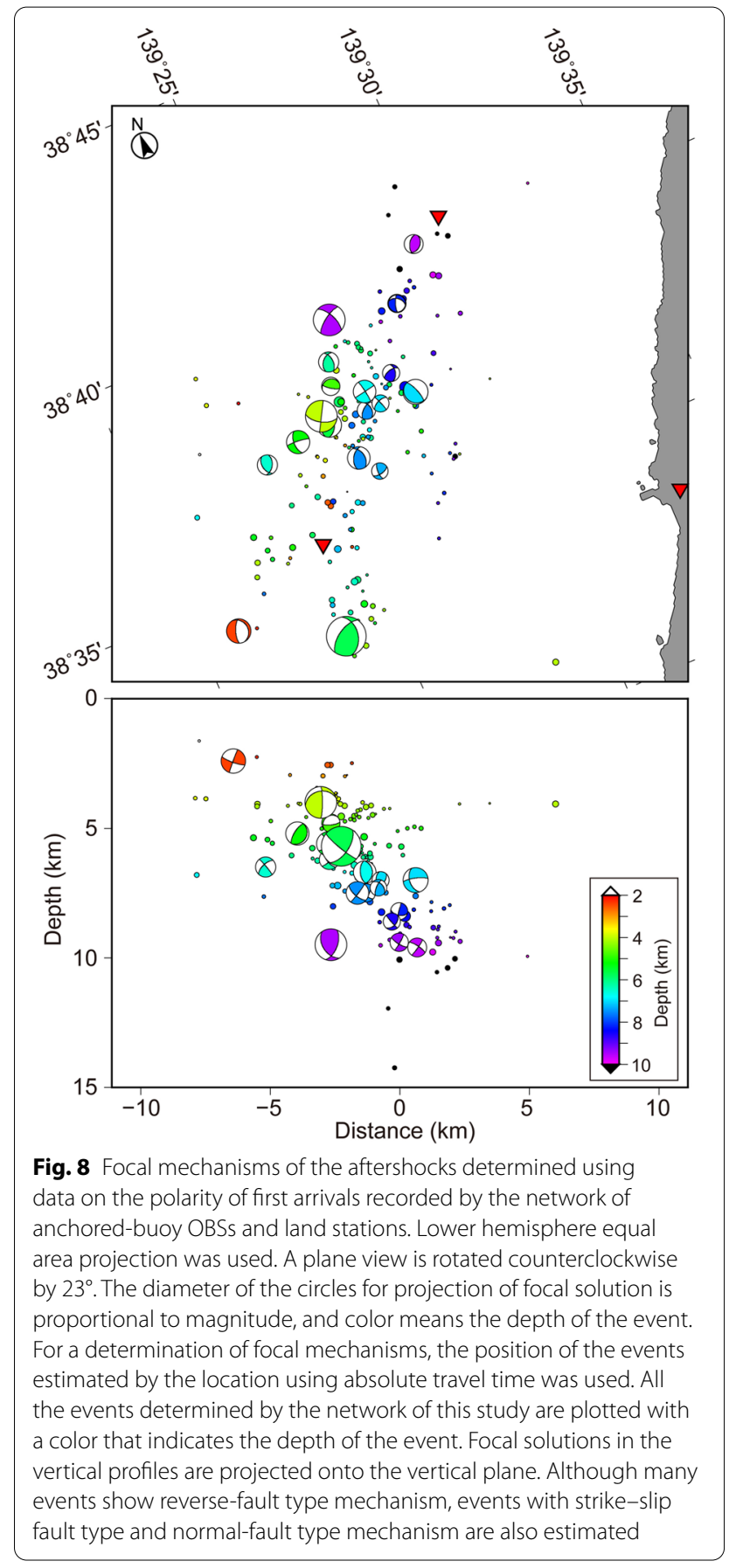

seismic network (F-net) data (Fukuyama et al. 1998). The focal mechanisms determined by the F-net also include a strike-slip fault type mechanism or a normal-fault type focal mechanism. Before the 2011 Tohoku-oki earthquake, an $\mathrm{E}-\mathrm{W}$ contraction strain rate was dominant in the source region of the 2019 Yamagata-oki earthquake (Yoshida et al. 2020). The 2011 Tohoku-oki earthquake changed the stress field and the source region of the 2019 
Yamagata-oki earthquake had an E-W extension strain rate after the 2011 Tohoku-oki earthquake by the occurrence of the 2019 mainshock (Yoshida et al. 2020). The events with the normal-fault type focal mechanism and the strike-slip fault type focal mechanism may reflect the present complex stress field. Most of the aftershocks occurred in the upper part of the upper crust. The limitation of the shallow activity of the aftershocks may also be correlated with the present stress field.

\section{Conclusions}

The 2019 Yamagata-oki earthquake with a magnitude of 6.7 occurred below the Japan Sea off Sakata, Yamagata prefecture. A tsunami with a height of $11 \mathrm{~cm}$ was observed at Tsuruoka, Yamagata prefecture. The mainshock was estimated to have a source mechanism of reverse-fault type with compression axis of WNW-ESE direction. The Yamagata-oki earthquake is inferred to relate to the Niigata-Kobe tectonic zone in the eastern margin of the Japan Sea. To obtain the precise distribution of the aftershocks, a marine seismic observation in the source region of the earthquake and temporary land seismic observation in the coastal area near the source region were planned. However, a seafloor seismic observation using ordinary free-fall pop-up type OBSs appeared to be difficult due to the shallow water, with a depth of less than $100 \mathrm{~m}$. A high noise environment was expected for a pop-up type OBS, and its use for observation might have been obstructed by the high fishing activity in the region. To avoid these difficulties, we developed a simple anchored-buoy type OBS for shallow water depths. A seafloor recorder with three-component velocity-type seismometer with a natural frequency of $15 \mathrm{~Hz}$ and a hydrophone was used. Because the recorder could observe seismic signals with any attitude, two orthogonal tiltmeters and an azimuth meter were installed to monitor the attitude of the package. The timing was based on a crystal oscillator. One of advantages of the recorder was a flat shape of its capsule with a height of approximately $11 \mathrm{~cm}$. To lower the seismic noise by the seafloor current, the height of an OBS capsule should be as low as possible. For installation at a shallow water depth, we developed a simple anchored-buoy system using fishing equipment. The system's buoy would inform sailing boats of the position of the system. The anchored-buoy OBS had anchors and a recorder at the end of a rope. The rope had a length of about $175 \mathrm{~m}$, and a buoy was connected to the other end of the rope.

We installed three anchored-buoy OBSs in the source region at a water depth of approximately $80 \mathrm{~m}$ on July 5, 2019. Two OBSs were recovered 8 days later. From the retrieved data records, it was found that changes in the attitude and temperature of the recorder were small during the observation. After the correction of the package's attitude, we estimated seismic noise during the observation. As a result, the seismic noise was small enough and comparable with that of the deep ocean floor at high frequencies. A temporal variation of the noise level was also small. The data obtained by the developed anchored-buoy OBS had sufficient quality for picking up the arrival times of the P-and S-waves and the polarity of the first arrivals.

The arrival times of the P- and S-waves were read from the records of the OBSs and land stations. In addition, we identified the polarity of first arrivals for large events. First, we located hypocenters by absolute travel times using a one-dimensional velocity structure that was estimated from the results of the seismic surveys. For the first location, station corrections were applied for precision. Next, we relocated the hypocenters using the DD method. Finally, the hypocenters of 175 aftershocks were obtained with spatial high resolution. The aftershocks were distributed at a depth range from 2.5 to $10 \mathrm{~km}$ and along a plane dipping to the southeast. The magnitude of the aftershocks ranged from 0.3 to 4.6.

The obtained aftershock distribution was compared to that determined by land seismic networks, and the hypocenters using land data only were about $5 \mathrm{~km}$ deeper than our results. The source region of the 2019 Yamagata-oki earthquake was estimated to be limited to the upper crust. There were some events away from the plane that was formed by many aftershocks. In consideration of the results of other large earthquakes that occurred previously in nearby areas, the 2019 Yamagata-oki earthquake may have had one large fault plane and a few small, conjugated faults. For events with magnitudes greater than 1.9, focal mechanisms could be determined using the polarities of the first arrivals. Most of the events had a focal solution with a compression axis of the WNW-ESE direction, which is consistent with the focal mechanism of the mainshock. Some aftershocks had a strike-slip type focal mechanism or a normal-fault focal mechanism. It is known that the stress field in the coastal area of the Japan Sea in northeastern Japan changed after the 2011 Tohoku-oki earthquakes. The limitation of depth distribution within the upper crust and the complexity of the focal mechanism in the aftershocks should rise from the present stress field.

\section{Abbreviations}

AMeDAS: Automated Meteorological Data Acquisition System; DD: Double difference; GNSS: Global Navigation Satellite System; JMA: Japan Meteorological Agency; JGD2011: Japanese Geodetic Datum 2011; NOWPHAS: The Nationwide Ocean Wave information network for Ports and HArbourS; NIED: The National Research Institute for Earth Science and Disaster Resilience; OBS: 
Ocean bottom seismometer; OVCXO: Oven Voltage-Controlled crystal oscillator; WGS84: World Geodetic System 84.

\section{Supplementary Information}

The online version contains supplementary material available at https://doi. org/10.1186/s40623-021-01562-6.

Additional file 1. Addtional table and figures.

\section{Acknowledgements}

The development of the simple anchored-buoy OBS and observation using the OBS could not be performed without the work of Messrs. T. Koike and S. Sawada from GEOSYS Inc. The authors express thanks to Drs. M. Masuda and H. Otsuka, Messrs. S. Ikezawa and T. Nishimoto of the Earthquake Research Institute, the University of Tokyo, for the temporary land seismic observation. The reading of wave arrivals and polarities by Ms. A. Saiki is appreciated. Comments from Dr. Saito and two anonymous reviewers were useful in improving the manuscript. This study was partly supported by the Earthquake and Volcano Hazards Observation and Research Program (Earthquake and Volcano Hazard Reduction Research) by the Ministry of Education, Culture, Sports, Science and Technology of Japan. Most figures were created using GMT (Wessel and Smith 1998)

\section{Authors' contributions}

MS played a leading role in this study, including the development of the anchored-buoy OBS, observation, data processing, analysis, and completion of the manuscript. SS led the temporal land seismic observation and carried out the data processing. TO also led the temporal land seismic observation. HS interpreted the results. YY, RH, KM, and TA contributed to the development of the anchored-buoy OBS and the observation. All authors read and approved the final manuscript.

\section{Funding}

This study was mainly supported by the Ministry of Education, Culture, Sports, Science, and Technology of Japan under the Earthquake and Volcano Hazards Observation and Research Program (Earthquake and Volcano Hazard Reduction Research). A part of this study was also funded by the Earthquake Research Institute, the University of Tokyo.

\section{Availability of data and materials}

The aftershock observations were performed as part of the Earthquake and Volcano Hazards Observation and Research Program (Earthquake and Volcano Hazard Reduction Research) by the Ministry of Education, Culture, Sports, Science and Technology of Japan. These data are available from the corresponding author on request. The information of hypocenters around the source region of the 2019 Yamagata-oki earthquake was obtained from the database established by the Earthquake Research Institute, the University of Tokyo, using information from the Japan Meteorological Agency (http://evrrss. eri.u-tokyo.ac.jp/db/jma.deck/index-j.html). The focal solutions of earthquakes determined by National Research Institute for Earth Science and Disaster Resilience were retrieved from the F-net catalog (https://www.fnet.bosai.go. jp/event/joho.php?LANG=en.). The above websites were last accessed in July 2021. Data for the wind speed and wave height were downloaded from the web sites of the JMA (https://www.data.jma.go.jp/gmd/risk/obsdl/) and Port Bureau, Ministry of Land, Infrastructure, Transport, and Tourism (https://nowph as.mlit.go.jp/pastdata/), respectively. The two websites were last accessed in October 2021

\section{Declarations}

Ethics approval and consent to participate

Not applicable.

\section{Consent for publication}

Not applicable.

\section{Competing interests}

The authors acknowledge that there are no conflicts of interest recorded.

\section{Author details}

${ }^{1}$ Earthquake Research Institute, The University of Tokyo, 1-1-1, Yayoi, Bunkyo-ku, Tokyo 113-0032, Japan. ${ }^{2}$ Research Center for Prediction of Earthquakes and Volcanic Eruptions, Graduate School of Science, Tohoku University, 6-6 Aza-Aoba, Aramaki, Aoba-ku, Sendai 980-8578, Japan. ${ }^{3}$ Miyazaki Observatory, Research Center for Earthquake Prediction, Disaster Prevention Research Institute, Kyoto University, 3884, Kaeda, Miyazaki 889-2161, Japan.

Received: 11 September 2021 Accepted: 14 December 2021

Published online: 04 January 2022

\section{References}

Abe K (1975) Re-examination of the fault model for the Niigata earthquake of 1964. J Phys Earth 23:349-366. https://doi.org/10.4294/jpe1952.23.349

Aoyagi Y, Shinohara M, Kaiho Y, Hotta H, Suyehiro K (1998) Hypocenter distribution in southern part of aftershock region of the 1993 Hokkaido Nansei-oki earthquake, precisely determined by digital ocean bottom seismographs. Zisin 2 50:451-459. https://doi.org/10.4294/zisin1948. 50.4_451 (in Japanese with English abstract)

Duennebier F-K, Sutton G-H (1995) Fidelity of ocean bottom seismic observations. Mar Geophys Res 17(6):535-555. https://doi.org/10.1007/BF012 04343

Fukuyama E, Ishida M, Dreger DS, Kawai H (1998) Automated seismic moment tensor determination by using on-line broadband seismic waveforms. Zisin 2 51:149-156. https://doi.org/10.4294/zisin1948.51.1_149 (in Japanese with English abstract)

Hirasawa T (1965) Source mechanism of the Niigata earthquake of June 16, 1964, as derived from body waves. J Phys Earth 13:35-66. https://doi.org/ 10.4294/jpe1952.13.35

Hirata N, Matsu'ura M (1987) Maximum-likelihood estimation of hypocenter with origin time eliminated using nonliear inversion technique. Phys Earth Planet Int 47:50-61. https://doi.org/10.1016/0031-9201(87)90066-5

Horikawa H (2008) Characterization of the 2007 Noto Hanto, Japan, earthquake. Earth Planets Space 60:1017-1022. https://doi.org/10.1186/BF033 52862

Kanazawa T, Shinohara M, Shiobara H (2009) Recent progress in seafloor earthquake observations and instruments in Japan. Zisin 2 61:S55-S68. https:// doi.org/10.4294/zisin.61.55

Kato A, The research team of aftershock observations for the 2004 mid-Niigata Prefecture earthquake (2007) High-resolution aftershock observations in the source region of the 2004 mid-Niigata prefecture earthquake. Earth Planets Space 59:923-928. https://doi.org/10.1186/BF03352030

Kusano F, Hamada N (1991) Re-investigation of hypocentral distribution of the 1964 Niigata Earthquake and its aftershocks. Zisin 2 44:305-313. https:// doi.org/10.4294/zisin1948.44.4_305 (in Japanese with English abstract)

McNamara D-E, Boaz R-I (2006) Seismic noise analysis system using power spectral density probability density functions - a stand-alone software package. Open-File Report 2005-1438. US Department of Interior, US Geological Survey. https://pubs.usgs.gov/of/2005/1438/

McNamara D-E, Buland R-P (2004) Ambient noise levels in the continental United States. Bull Seismol Soc Am 94(4):1517-1527. https://doi.org/10. 1785/012003001

Miyake H, Koketsu K, Hikima K, Shinohara M, Kanazawa T (2010) Source fault of the 2007 Chuetsu-oki, Japan, earthquake. Bull Seism Soc Am 100:384391. https://doi.org/10.1785/0120090126

Mori J, Boyd T (1985) Seismological evidence indicating rupture along an eastward dipping fault plane for the 1964 Niigata, Japan earthquake. J Phys Earth 33:227-240. https://doi.org/10.4294/jpe1952.33.227

National Research Institute for Earth Science and Disaster Resilience (2021) Earthquake mechanism information. https://www.fnet.bosai.go.jp/event/ joho.php?LANG=en. Accessed 27 July 2021

Peterson J (1993) Observations and modeling of seismic background noise. Open-File Report 93-322. US Department of Interior, US Geological Survey. https://doi.org/10.3133/ofr93322

Reasenberg P-A, Oppenheimer D (1985) FPFIT, FPPLOT and FPPAGE: Fortran computer programs for calculating and displaying earthquake fault-plane 
solutions. Open-File Report 85-739, US Department of the Interior, US Geological Survey. https://doi.org/10.3133/ofr85739

Sagiya T, Miyazaki S, Tada T (2000) Continuous GPS array and present-day crustal deformation of Japan. Pure Appl Geophys 157:2303-2322. https:// doi.org/10.1007/978-3-0348-7695-7_26

Satake K (1985) The mechanism of the 1983 Japan Sea earthquake as inferred from long-period surface waves and tsunamis. Phys Earth Planet Int 37:249-260. https://doi.org/10.1016/0031-9201(85)90012-3

Satake K, Abe K (1983) A fault model for the Niigata, Japan earthquake of June 16, 1964. J Phys Earth 31:217-223. https://doi.org/10.4294/jpe1952.31.217

Sato T, No T, Kodaira S, Takahashi N, Kaneda Y (2014) Seismic constraints of the formation process on the back-arc basin in the southeastern Japan Sea. J Geophys Res Solid Earth 119:1563-1579. https://doi.org/10.1002/2013J B010643

Shiba Y, Uetake T (2011) Rupture process of the 1964 M MMA 7.5 Niigata earthquake estimated from regional strong-motion records. Bull Seism Soc Am 101:1871-1884. https://doi.org/10.1785/0120100242

Shinohara M, Kanazawa T, Yamada T, Nakahigashi K, Sakai S, Hino R, Murai Y, Yamazaki A, Obana K, Ito Y, Iwakiri K, Miura R, Machida Y, Mochizuki K, Uehira K, Tahara M, Kuwano A, Amamiya A, Kodaira S, Takanami T, Kaneda Y, Iwasaki T (2008) Precise aftershock distribution of the 2007 Chuetsu-oki earthquake obtained by using an ocean bottom seismometer network. Earth Planets Space 60:1121-1126. https://doi.org/10.1186/BF03353147

Tanioka Y, Satake K, Ruff L (1995) Total analysis of the 1993 Hokkaido Nanseioki earthquake using seismic wave, tsunami, and geodetic data. Geophys Res Lett 22:9-12. https://doi.org/10.1029/94GL02787

Urabe T, Tsukada S (1991) A workstation-assisted processing system for waveform data from microearthquake networks. Abstracts of Spring Meeting of Seismological Society of Japan, 70 (in Japanese)

Urabe T, Suyehiro K, Iwasaki T, Hirata N, Kanazawa T, Nishizawa A, Shimamura H (1985) Aftershock distribution of the 1983 Japan Sea earthquake as determined from helicopter-dispatched OBS observation. J Phys Earth 33:133-147. https://doi.org/10.4294/jpe1952.33.133

Waldhauser F, Ellsworth W-L (2000) A double-difference earthquake location algorithm: method and application to the northern Hayward fault. Bull Seismol Soc Am 90:1353-1368. https://doi.org/10.1785/0120000006

Watanabe $H$ (1971) Determination of earthquake magnitude at regional distance in and near Japan. Zisin 2 24:189-200. https://doi.org/10.4294/ Zisin 1948.24.3_189 (in Japanese with English abstract)

Wessel P, Smith W-H-F (1998) New, improved version of the generic mapping tools released. Eos Trans AGU 79:579. https://doi.org/10.1029/98EO00426

Yamada T, Mochizuki K, Shinohara M, Kanazawa T, Kuwano A, Nakahigashi K, Hino R, Uehira K, Yagi T, Takeda N, Hashimoto S (2008) Aftershock observation of the Noto Hanto earthquake in 2007 using ocean bottom seismometers. Earth Planets Space 60:1005-1010. https://doi.org/10. 1186/BF03352860

Yoshida K, Uchida N, Hiarahara S, Nakayama T, Matsuzawa T, Okada T, Matsumoto Y, Hasegawa A (2020) 2019 M6.7 Yamagata-Oki earthquake in the stress shadow of 2011 Tohoku-Oki earthquake: was it caused by the reduction in fault strength? Tectonophysics 793:228609. https://doi.org/ 10.1016/j.tecto.2020.228609

\section{Publisher's Note}

Springer Nature remains neutral with regard to jurisdictional claims in published maps and institutional affiliations.

\section{Submit your manuscript to a SpringerOpen ${ }^{\circ}$ journal and benefit from:}

- Convenient online submission

- Rigorous peer review

- Open access: articles freely available online

- High visibility within the field

- Retaining the copyright to your article

Submit your next manuscript at $\boldsymbol{\nabla}$ springeropen.com 